\title{
A Study on the Development of a Life-Focused Foreign Language Acquisition Scale for Preschool Children: English Sample
}

Banu USLU ${ }^{1}$

Aysel ÇAĞDAŞ²

\begin{abstract}
Designing scales for preschool children in order to promote their foreign language acquisition is a complex struggle that likely involves efforts at many stages within the process of early childhood education. There is a wide range of options currently being considered for how to best measure children's foreign language learning. The use of scientifically validated language scale is regarded as an important method. Despite a large body of evidence in terms of reliable indicators of foreign language acquisition in preschool children, there has not been a standardized, quick, easy, functional and life-based scale. The purpose of the present study was to develop a valid and reliable "LifeFocused Foreign Language Acquisition Scale" (LFFLAS) for the evaluation of foreign language proficiency of preschool children who are 50-74 months-old. The study was conducted in the general survey model. 120 children from private kindergartens affiliated with the Konya National Education Directorate participated in the study. Findings related to the construct validity of the scale were obtained by factor analysis method. Based on Tetrachoric Factor Analysis, 4 sub-dimensions were found. Findings related to the reliability of the scale were obtained with the KR 20 (internal consistency) and score invariance techniques. The findings of the study revealed that the reliability coefficients related to internal consistency and score invariance of sub-scales related to LFFLAS were sufficient and the scale is valid and reliable in measuring preschool children's foreign language acquisition. There were significant differences in the sub-scales of the scale depending on gender and age variables.
\end{abstract}

\section{Suggested Citation:}

Uslu, B. \& Çağdaş, A. (2017) A Study on the Development of a Life-Focused Foreign Language Acquisition Scale for Preschool Children: English Sample, International Journal of Academic Research in Education, 3(1), 33-53 DOI: 10.17985/ijare.398952

\footnotetext{
${ }^{1}$ Asst. Prof., Alanya Alaaddin Keykubat University, banuuslu@gmail.com

2 Asst. Prof., Selçuk University, aysel-cagdas@ hotmail.com
} 


\section{INTRODUCTION}

The preschool period is the basis of life. Within preschool education, suitable learning areas should be arranged to support all developmental areas of children and they should be prepared for their elementary education by taking into account their interests and needs. Preschool education should support children's foreign language learning so that they can speak fluently and express themselves correctly (MNE, 2013). Additionally, many countries worldwide have made it a priority consideration to begin early childhood instruction of English as a foreign language.

For over two decades, Turkey has legislated teaching English as a foreign language in public schools (known under the acronym TEFL). As mandated by the Ministry of Education in Turkey, students are required to begin studying English in the second grade of elementary school. The educational goal is to communicate in English and be able to read and understand it by the end of elementary school. When these children finish elementary school they are expected to read books that are written in English and communicate with foreigners coming from different parts of the world. Before 1997, foreign language classes used to begin in the 6th grade in Turkey. A decade later, it was moved to 4th grade, and in 2014 they began teaching English as a foreign language in the 2 nd grade. The reason for all of this change stems from the advantages of learning a foreign language at an early age (Bekleyen, 2016).

The preschool period is the period when the brain is ready to learn and hungry the most. In this critical period when these windows of opportunity are still open, it is important to improve positive attitudes and behaviors towards a foreign language. For this reason, foreign language teaching practices for preschool children is a prevailing topic discussed and studied worldwide. Therefore, concerted effort in academic research has been focused on developing programs for preschool children's foreign language learning, in planning new teaching approaches and strategies to improve their language skills and proficiency, and in creating assessment and evaluation tools which take into account both receptive and expressive skills (Krashen, 1981).

The intent of the LFFLAS was to develop a valid and reliable scale which will have two main benefits: 1) measuring Turkish preschool children's English foreign language acquisition, and 2) providing a rigorously tested, academically sampled vocabulary list (comprised of words most commonly used or needed for the child to interact within their own living environment) which can shape the formation of foreign language curricula. The testing done via the scale will therefore inform educators not only of the children's language skills, but can be implemented to lead instruction to cover the first essential 100 words used in daily life. The LFFLAS is the scale developed specifically for Turkish preschool children including their cultural, religious and national features.

Within the arena of measuring foreign language acquisition, assessment is done by measuring the four skills: listening, reading, speaking and writing. Listening and reading are known as receptive skills, while speaking and writing are known as productive/expressive skills. Since the current target group of the scale is preschool children who have little experience with reading or writing, the scale is limited to measuring two skill sets: the receptive skill of listening comprehension and the productive skill of speaking (Thal, O'Hanlon, Clemmons and Fralin, 1999).

During the preschool period, connecting teaching and learning processes to real life situations provides effective learning not only in foreign language teaching but also improving the knowledge of the first language. This type of program and approach allows children to acquire not only cognitive but also emotional sensations that lead learning in all fields. These findings are in alignment with the control value theory of achievement emotions, and contribute to developing a high level of self-efficacy (Pekrun, 2006). 
While learning a foreign language it is not enough just to use the language (MNE, 2013), but this also provides an effective method at this pivotal time period in child development to structure children for academic successes throughout their schooling (Patterson, DeBaryshe, Ramsey, 1990).

Considering the studies conducted in the field it can be said that the comparison of monolingual and bilingual children's language skills are examined (Bialystok, 2010; Bialystok \& Martin, 2004) According to these studies, children who learn a foreign language at an early age exhibit high language and learning performances. Linguists, psychologists, and sociologists have investigated bilingual populations from different perspectives in order to understand how bilingualism affects cognitive abilities like memory, perception, and metalinguistic awareness. In line with linguistically related studies of bilingual children, Ellen Bialystok explores language and cognitive development in bilingual children, primarily focusing on the preschool years (Minami, 2002). One of the most important developments in the field of education in recent years has been the emphasis on the development of foreign language development in preschool years. There has been an increasing interest in studies regarding foreign language teaching in early childhood education (Martinez and Lesaux, 2011; Yoneda, 2012). Because of the lacking component of reading and writing in foreign language education during early childhood, this early life language acquisition parallels the same development as acquiring one's native language orally. We acquire as we are exposed to samples of the foreign language which we understand. This happens in much the same way that children pick up their first language - with no conscious attention to language form. We learn, on the other hand, via a conscious process of study and attention to form and rule learning (Lightbown, Spada 1999). Early childhood language teachers will therefore be most effective when their methods include these two aspects - natural acquisition and learning. While the two terms denote two clearly different processes, for individual language learners there is typically some overlap between natural acquisition and instructed learning (Pinter, 2011). The LFFLAS bridges this gap by both its potential in leading vocabulary instruction, as well as its focus on language skills for daily life interaction which provide the children with an interaction-based language learning environment.

With this increasing focus on early childhood language teaching, the lack of scientifically-based measurement tools for the acquisition of foreign languages in this period is problematic area which needs academic research attention. The research on preschool English language learners is limited, and there is a need to develop assessments which measure language skills (VanTol, 2009).

According to Black (2004) there is tremendous variability in the quality of assessment instruments that are available and used with young children. Early childhood educators and researchers agree that there is no perfect test. Each measure has its strengths and weaknesses. Some instruments lack the technical and psychometric qualities that assure reliable and valid test scores. Others are not appropriate for the diversity of children in a particular community, do not measure all the dimensions of children's early development and learning, and/or do not measure the full range of abilities in the domains they cover. Despite the limitations of some assessment instruments, there is a sufficient number of psychometrically sound instruments available. The challenge is selecting an instrument that will be most appropriate and useful for a specific purpose.

According to many of the researchers mentioned below in Table 1 assessing native and foreign language is an intensive and time-consuming process. A variety of strategies should be used, from language sampling and formal tests to observations of children's behaviors in natural settings. Especially when testing with preschool age children, methods should be presented in a way that the child's psychology is heavily weighted so that their experience is a positive one. A few particularly noteworthy tests for preschoolers are presented in the table below. 
Table 1. Language Tests that are used in Preschool Period

\begin{tabular}{|c|c|c|}
\hline Test & Author/Publisher & Description \\
\hline $\begin{array}{l}\text { Receptive-Expressive } \\
\text { Emergent Language Test } \\
\text { (3rd ed.) }\end{array}$ & $\begin{array}{l}\text { Bzoch, K., League, R., \& } \\
\text { Brown, V. (2003). Austin, } \\
\text { TX: PRO-ED. }\end{array}$ & $\begin{array}{l}\text { The REEL-2 is a revision of an earlier tool. } \\
\text { Designed for using in early intervention } \\
\text { programs, it assesses both receptive and } \\
\text { expressive language via parent interviews of } \\
\text { infants and toddlers. }\end{array}$ \\
\hline $\begin{array}{l}\text { Boehm Test of Basic } \\
\text { Concepts 3-Preschool } \\
\text { Version }\end{array}$ & $\begin{array}{l}\text { Boehm, A. (2001). New } \\
\text { York: Psychological } \\
\text { Corporation. }\end{array}$ & $\begin{array}{l}\text { The Boehm Preschool Version assesses the } \\
\text { knowledge of basic concepts in children aged } 3 \text { to } \\
5 \text { years. }\end{array}$ \\
\hline $\begin{array}{l}\text { Sequenced Inventory of } \\
\quad \text { Communication } \\
\text { Development (Rev. ed.) }\end{array}$ & $\begin{array}{l}\text { Hendrick, D., Prather, E., } \\
\text { \& Tobin, A. (1984). } \\
\text { Austin, TX: PRO-ED. }\end{array}$ & $\begin{array}{c}\text { The SICD-R is a diagnostic battery useful with } \\
\text { children whose functional levels range from } 4 \\
\text { months to } 4 \text { years. }\end{array}$ \\
\hline $\begin{array}{l}\text { Test of Early Language } \\
\text { Development-(3rd ed.) }\end{array}$ & $\begin{array}{l}\text { Hresko, W., Reid, D. K., \& } \\
\text { Hammill, D. (1999). New } \\
\text { York: Psychological } \\
\text { Corporation. }\end{array}$ & $\begin{array}{c}\text { The TELD-3 is a diagnostic language test for } \\
\text { children from } 2.0 \text { to } 7.11 \text { years of age. It provides } \\
\text { data on receptive and expressive language } \\
\text { systems and syntactic/semantic language } \\
\text { features. }\end{array}$ \\
\hline $\begin{array}{c}\text { Preschool Language Scale } \\
\text { (4th ed.) and Preschool } \\
\text { Language Scale-Spanish } \\
\text { Edition }\end{array}$ & $\begin{array}{l}\text { Zimmerman, I., Steiner, } \\
\text { V., \& Pond, R. (2002). } \\
\text { New York: Psychological } \\
\text { Corporation. }\end{array}$ & $\begin{array}{c}\text { The PLS-4 assesses auditory comprehension and } \\
\text { expressive communication in children from } 2 \\
\text { weeks of age to } 6 \text { years } 11 \text { months. }\end{array}$ \\
\hline $\begin{array}{l}\text { Dynamic Indicators of } \\
\text { Early Literacy Skills } \\
\text { (DIBELS) }\end{array}$ & Kaminski \& Good, 1996 & $\begin{array}{l}\text { Measures early language skills of alphabet } \\
\text { information, sound awareness, fluency, } \\
\text { vocabulary and comprehension skills }\end{array}$ \\
\hline $\begin{array}{c}\text { Peabody Picture } \\
\text { Vocabulary Test (PPVT) }\end{array}$ & Dunn \& Dunn, 1997 & $\begin{array}{l}\text { The development of vocabulary knowledge of 2- } \\
\qquad 12 \text { year-olds }\end{array}$ \\
\hline $\begin{array}{l}\text { Phonological Awareness } \\
\text { Literacy Screening (PALS) }\end{array}$ & $\begin{array}{l}\text { Invernizzi, M., Sullivan, } \\
\text { A., \& Meier, J. (2001) }\end{array}$ & $\begin{array}{l}\text { Literacy screening, diagnosis, and progress } \\
\text { monitoring of } 4-5 \text { year-olds. }\end{array}$ \\
\hline $\begin{array}{c}\text { Comprehensive Test of } \\
\text { Phonological Processing. } \\
\text { (CTOPP) }\end{array}$ & $\begin{array}{c}\text { Wagner, R.K., Torgesen, } \\
\text { J. K., \& Rashotte, C.A. } \\
\text { (1999). }\end{array}$ & Phonological abilities of 4-6 year-olds. \\
\hline $\begin{array}{l}\text { Phonological Abilities Test } \\
\text { (PAT-M) }\end{array}$ & $\begin{array}{l}\text { Muter, Hulme \& } \\
\text { Snowling } \\
\text { (1999) }\end{array}$ & $\begin{array}{l}\text { Assesses the nature and extent of a child's } \\
\text { phonological weakness, } 5-7 \text { year-olds }\end{array}$ \\
\hline $\begin{array}{l}\text { Test of Awareness of } \\
\text { Language Segments } \\
\text { (TALS) }\end{array}$ & Sawyer, (1987) & $\begin{array}{l}\text { Awareness of the segments of spoken language, } \\
5-7 \text { year-olds }\end{array}$ \\
\hline $\begin{array}{l}\text { Test of Phonological } \\
\text { Awareness (TOPA) }\end{array}$ & $\begin{array}{l}\text { Torgesen \& Bryant } \\
\text { (1994) }\end{array}$ & $\begin{array}{l}\text { Measures young children's ability to }(\mathrm{a}) \text { isolate } \\
\text { individual phonemes in spoken words and (b) } \\
\text { understand the relationships between letters and } \\
\text { phonemes in English, 5-8 year-olds }\end{array}$ \\
\hline Test de Descoeudres & Descoeudres, 1930 & $\begin{array}{c}\text { Daily vocabulary knowledge of children, 4-6 year- } \\
\text { olds }\end{array}$ \\
\hline
\end{tabular}


When Table 1 is examined, it is seen that during preschool period the tests tend to evaluate preschool children's general language development, language proficiency, and language skills.

In the literature, it can be said that there are not many studies to measure foreign language skills. Milton \& Daller (2007), Milton (2009) examined the relationship between English and French vocabulary at preschool level, their difficulty level and word length. In another study (2009), Milton stated that it is not possible to achieve meaningful results in vocabulary and vocabulary analysis and suggested using different measurement tools together in order to obtain meaningful results for the measurement of foreign language skills in preschool period. Similarly, the relationship between vocabulary knowledge and vocabulary difficulty level in foreign language acquisition of preschool children was studied by Willis and Ohashi (2012). Researchers used vocabulary to calculate word frequency for the scale and word length as a criterion for determining the level of difficulty. These studies show us that the measurement tools used by field researchers to measure foreign language acquisition of preschool children are usually word lists and word length. The most important criticism put forward by both researchers and those concerned is the inadequacy of standardized measurement tools for the acquisition of foreign languages in preschool period.

It is clear that vocabulary is an important feature of language learning but here the question is what features a standard test should have. Fremer and Wall (2004) stated that a standard test should have features such as: objectives results, cost-effectiveness, technical quality and standards, fairness, and evolutionary improvement. Furthermore, principles of quality assessment defined by McMillan are as follows: a qualified assessment adheres to specific psychometric standards, validity and reliability, among other principles. An expanded definition of quality assessment had the following criteria: (a) clear and appropriate learning targets, (b) appropriateness of assessment methods, (c) validity, (d) reliability, (e) fairness, (f) positive consequences, (g) alignment, and (h) practicality and efficiency (McMillan, 2007). In addition, Brown (2004) states that effective tests should be practical and not expensive, they should stay within appropriate administration time constraints, be relatively easy to apply, and have a specific and time efficient scoring procedure.

In Turkey however, there are inconsistencies and ambiguities in the process of evaluating children's foreign language acquisition since the focus is on learning a language not acquiring it. Schools, teachers and researchers have problems in finding and choosing appropriate assessment tools. Most of the tests expressed in the table above are adapted to Turkish haphazardly and are applied to children in the preschool period. There is no country-wide program or academically-based testing which has been adopted. It is observed that a gamut of applications is carried out by academicians who are working in preschool and developmental psychology areas mostly for research and academic purposes. While teaching, educational institutions use preschool curricula at their own initiative which are already ready or they follow preschool foreign language teacher guidebooks that are used by foreign language teachers. Additionally, there are reliability and validity issues of the assessment tools used in the evaluation processes. Some of the instruments marketed as preschool language and foreign language instruments have limited item selection and subscale development, poor reliability and validity (especially predictive validity), and a lack of rationale for determining cutoff scores. This is particularly true of the selfdeveloped tests that have been created by some states and school districts. Assessment instruments that produce totally inconsistent results over different periods of time, over different samples of questions, or over different raters cannot provide valid information about the performance being measured (Love, 2001; Mann and Powers, 1997; Shepard, Taylor and Kagan, 1996).

From this point of view, it is important to create a standardized test that is valid and reliable, especially in evaluating children's foreign language acquisition. Though there are samples of language scales developed for preschoolers in the literature, within Turkey it is hard to mention the existence of such a 
scale measuring preschool children's foreign language acquisition. Creating a standardized foreign language scale considering the cultural, religious and national values in Turkey for preschoolers will provide important contributions to the programs and practices that will be prepared. It is thought that children can show important progress in basic skills related to foreign languages before they begin elementary school. In order to prepare any program, a standard assessment tool for Turkish preschool children is needed to discover what knowledge the children start with, and to see whether the methods and techniques used within the program are effective.

\section{Purpose of the study}

The purpose of the present study was to develop a valid and reliable "Life-Focused Foreign Language Acquisition Scale" (LFFLAS) for the evaluation of foreign language acquisition of preschool children who are 50-74 months-old.

\section{METHOD}

In the present study, a survey model was used based on the quantitative research paradigm and the scale was developed by taking the steps of Dunn and Dunn into consideration (1997). In this context, firstly, literature review was conducted and an item pool was formed. Then, expert opinion was obtained and the pilot study is carried out. After all these processes Factor Analysis and reliability calculations were carried out for validity.

\section{Population and Study Group}

The population of the present study is 50-74 months-old Turkish children attending preschool institutions where they receive instruction of English as a foreign language. The study was conducted on this study group since the population of the study was very extensive $(22,712$ preschool children) in Konya and included all the 50-74 months-old Turkish children who were going to preschool education institutions in Turkey. Approximately $90 \%$ of these children are studying in the districts of the city center (Selçuklu, Meram, Karatay). Taking into account the granting of permission necessary to conduct the study, and to be able to reach the participants in the research group easily, 120 children were selected from the preschool/kindergartens of private schools located in one of the central districts of the province during the 2015-2016 academic year. Firstly, preschool education institutions providing foreign language education in the Selçuklu district of Konya were determined in order to create a sample for the application practice of the scale. Seven private schools providing foreign language education to their students in this area were identified. In correspondence with these schools, a total of 4 schools had volunteered to work with the researcher. Preschool children between the ages of 50-74 months were included in sample and the tests of the scale were carried out on all preschool students of these four schools. The characteristics of the children participating in the study were obtained by the personal information form prepared by the researcher. Children learning English as a foreign language between the ages of 50-74 months in their schools were included in the study group. Applications were carried out by the researcher in the schools the children were attending.

\section{Data Collection Tools}

The purpose of the present study was to create a Life-Focused Foreign Language Acquisition Scale. For this reason, information about LFFLAS has been given in terms of its validity and reliability studies. In addition, the child and family information form was applied during the scale development process. 


\section{Child and Family Information Form}

The information form developed by the researcher was prepared to obtain information about the children and their parents who were in the sample group for scale development. In the form, there were questions about children's age, gender, duration of preschool education, education in private or public schools and children's parents' education status, whether they have been abroad or not, and their income level.

\section{Life-Focused Foreign Language Acquisition Scale (LFFLAS)}

LFFLAS, which was created by the researcher, was planned as a tool to measure and evaluate foreign language acquisition of children aged 50-74 months in the preschool period. In the development process of the scale, Literature Review, Expert Opinions, Examining Course Books, Descriptive Analysis of Foreign Language Concepts, Delphi Panel, Pilot Study, Item Analysis, Test Analysis, Validity Analysis and Reliability Analysis were carried out. While creating the scale validity and reliability analyzes were carried out. In this phase, descriptive factor analysis and item analysis were applied. All these processes are explained in detail within the findings section of the article.

One of these theoretical analyses is called the conceptual validity (construct/model validity) test and predicts the theoretical analysis of whether or not the questions developed to measure a variable are measuring that variable or are related to that variable. Factor analysis is one of the most frequently used methods for testing the conceptual validity of a scale (Bacon, Sauer and Young, 1995).

Validity refers to how well an assessment tool or scale measures what it is purported to measure (Reuterberg \& Gustafsson, 1992). One of these theoretical analyses is called the conceptual validity (construct validity) test and predicts the theoretical analysis of whether the questions developed to measure a variable measure that variable or are related to that variable. Factor analysis is one of the most frequently used methods for testing the conceptual validity of a scale (Bacon, Sauer \& Young, 1995).

For dichotomous data, conduct a familiar factor analysis on the matrix of tetrachoric inter-item correlations rather than on the matrix of Pearson correlations. When the items are based on ordered categories (e.g., Likert scales), familiar factor analyses should be conducted on the matrix of polychoric inter-item correlations rather than on the matrix of Pearson correlations. Tetrachoric and polychoric correlations are based on the assumption that the response categories (dichotomous or Likert scale) are actually proxies for unobserved, normally distributed variables. Factor analysis of tetrachoric or polychoric correlation matrices are essentially factor analyses of the relations among latent response variables that are assumed to underlie the data and that are assumed to be continuous and normally distributed (Panter, Swygert, Dahlstrom, \& Tanaka, 1997).

Because of the 1-0 scoring of the scale (dichotomous data) a Tetrachoric Factor Analysis was performed on this matrix was established in the present study. The suitability of the data for factor analysis was examined by the Kaiser-Meyer-Olkin (KMO) coefficient and the Barlett sphericity test. For the suitability of the data for factor analysis the Kaiser-Meyer-Olkin (KMO) value should be more than .60 and the calculated chi-square value of Barlett's test should be statistically significant (Büyüköztürk, 2004). In LFFLAS the sample consistency coefficient (KMO) and $\chi 2$ value of the Barlett Sphericity Test were found to be satisfactory. As a result of the factor analysis it is seen that the scale has four sub-dimensions. These sub-dimensions are: "Vital Vocabulary", "Crucial Vocabulary", "Social Vocabulary" and "Useful Vocabulary." After this stage, reliability analyzes were made on each sub-dimension and on the whole scale. In these analyzes, KR-20 and split-half methods were used. 


\section{The Scoring of Life-Focused Foreign Language Acquisition Scale}

The first sub-dimension of the scale is named "Vital Vocabulary." There are 23 questions on this dimension and these questions are: b2-24, b2-23, b2-16, b2-18, b3-34, b3-19, b1-4, b3-30, b2-21, b2-17, b3-32, b3-5, B3-18, b2-22, b2-4, b3-6, b3-9, b3-33, b2-12, b3-4, b3-17, b3-8 and b2-8. The second subdimension of the scale is named "Crucial Vocabulary." There are 25 questions on this dimension and these questions are: b3-27, b3-12, b3-14, b3-1, b2-11, b2-3, b2-7, b3-21, b1-3, b2-2, b3-23, b2-6, B2-1, b2-25, b2-1, b3-10, b3-7, b3-3, b2-10, b2-9, b3-28, b3-26, b3-13, b3-2 and b2-15. The third subdimension of the scale is named "Social Vocabulary." There are 19 questions on this dimension and the questions are: b1-9, b2-13, b2-5, b1-8, b3-24, b1-10, b2-28, b2-20, b3-38, b2-19, b3-31, b1-7, b1-6, b337, b3-22, b1-5, b1-2, b2-14 and b3-29. The fourth dimension of the scale is named as "Useful Vocabulary" and has 11 questions. They are: b3-39, b1-11, b3-15, b2-26, b2-27, b3-16, b3-36, b3-11, b335, b3-25 and b3-20. Each correct answer is scored as (1) and each false or ambiguous answer is scored as (0).

Table 2. Knowing Self

\begin{tabular}{|c|c|c|}
\hline Items & 11 Questions & Each correct respond is scored 1 point \\
\hline b1-1 & 1. Hello/ Hi. Please sit down.. & \\
\hline b1-7 & 2. Do vou go to school? & \\
\hline b1-11 & 11. Can vou please open the door? & \\
\hline
\end{tabular}

Table 3. Useable Vocabulary

\begin{tabular}{lll}
\hline Items & 28 words & Extra vocabularv is not scored \\
\hline b2-1 & B2.1 STAR & b2.1a shapes, b2.1b circle, b2.1c triangle, b2.1d \\
\hline b2-10 & B2. 10 CAR & b2.10a bus, b2.10b train/fast train, b2.10c plane \\
\hline b2-14 & B2. 14 BALL & \\
\hline b2-24 & B2. 24 TURKISH FLAG & b2.24.1 Turkish monev, b2.24.2 Turkish Liras, \\
\hline b2 28 & B2. 28 WASHING/WASH & \\
\hline
\end{tabular}

Table 4. Recognizable Vocabulary

\begin{tabular}{ll}
\hline Items & 39 words \\
\hline b3-1 & 1. SHE IS DANCING AT A WEDDING /HAVING FUN \\
\hline b3-10 & 2. THE TRAFFIC LIGHT SAYS GO/YOU CAN DRIVE OR WALK NOW \\
\hline b3-21 & 3. IT IS A GIRL \\
\hline b3-32 & 4. \\
\hline
\end{tabular}

\section{Data Analysis}

In the present study to test the validity of the scale the Tetrachoric Exploratory Factor Analysis method was used. These analyses of the scale were made via the Mplus program. In the reliability test, KR-20 and 
split-half methods were used. While comparing preschool children's foreign language acquisition in terms of their gender One Samples t Test was used. To compare the relation between their ages and language acquisition scores Pearson Moments Multiplication Correlation Coefficient technique was used. These analyzes were performed with the SPSS 21.0 program.

\section{FINDINGS}

In this part, findings related to the validity and reliability of LFFLAS are included. Subsequently, using the validity and reliability data obtained from the study, children's foreign language acquisition were compared in terms of gender and age.

a. Findings related to validity of a measurement tool or a scale is related to the degree to which it measures the variant that is desired to be measured. In order to test the validity of 'Life-Focused Foreign Language Acquisition Scale,' content validity, construct validity, known group validity and item analysis techniques were applied. The detailed description of the steps taken to validate the scale is as follows.

\section{Content Validity}

In content validity the answer to the question "Do the test items adequately reflect the behaviour to be measured?" is searched. In order to find an adequate answer to this question, literature review, children's books and tools that are developed for similar purposes were examined, the expert opinions were asked, and the Delphi Panel was carried out. The steps taken at this stage are explained in detail below.

\section{Literature Review}

In order to develop Life-Focused Foreign Language Acquisition Scale, firstly a literature review is carried out. In this context, the language development characteristics of 50-74 months-old children, their daily language use situations, and concepts that they frequently prefer have been examined. At this stage, interviews are made with five specialists. These specialists include three professors who completed their studies within Preschool and Child Development Departments and one professor from the Curriculum Department and one professor from the Assessment and Evaluation Department of education faculties. All of the experts who participated had conducted studies on developing an assessment tool in their own fields.

\section{Descriptive Analysis of Preschool Period Foreign Language Books}

After the literature review, course-books in both target and native language used for 50-74 months-old children in preschools are examined. Three sets, each consisting of at least ten books, were selected. These books had a concept of teaching English through flashcards, stories, puppets, posters, songs and short stories. Based on expert opinions in these three sets, criteria were developed for content scanning. To help foreign language teachers to make accurate comparisons of a child's receptive and expressive vocabulary skills these criteria are based on foreign and native language word categories. These are: nouns, verbs, pronouns, adverbs, adjectives, conjunctions, prepositions, phrasal verbs, question words, numbers, quantifiers, interjections, colors, reduplications and spoken language phrases. In this way, the words used frequently are determined. The words in these three sets are assigned to the word counting program (which calculates the frequency of the words in a text), and the most repeated words in the relevant age group are determined. In Table 5 descriptive analysis results that formed the basis for the questions in the scale are given. 
Table 5. Range of the Words in Native Language and English Language Books of 50-74 Months-old Children

\begin{tabular}{lll}
\hline Type of vocabulary & $\begin{array}{l}\text { Number of } \\
\text { words }\end{array}$ & f \\
\hline Nouns & 248 & 1124 \\
\hline Verbs & 205 & 938 \\
\hline Pronouns & 45 & 764 \\
\hline Adverbs & 104 & 277 \\
\hline Adiectives & 80 & 239 \\
\hline Coniunctions & 14 & 135 \\
\hline Prepositions & 10 & 107 \\
\hline Phrasal Verbs & 69 & 99 \\
\hline Question Words & 15 & 97 \\
\hline Numbers & 5 & 85 \\
\hline Quantifiers & 5 & 49 \\
\hline Interiections & 11 & 21 \\
\hline Colors & 3 & 9 \\
\hline Reduplications & 6 & 2 \\
\hline Spoken Language Phrases & 2 & \\
\hline
\end{tabular}

\section{Expert Opinions}

The results of the 50-74 months-old children foreign language concept and descriptive analysis conducted by the word counting program were examined by three professors from preschool and child development departments and three preschool teachers working with this age group. By doing so, depending on children's ages and development features the appropriateness of the words for this age group is examined in terms of children's language development. As a result of the evaluations of the expert group, it was concluded that the scale had content validity.

\section{Delphi Panel}

In order to test conformity of the concepts in the pilot study in terms of age group and scale development principles, a Delphi Panel was organized. A rubric was prepared and the words derived from the books examined were attached to it according to their frequency levels. The experts were asked to complete it within 3 weeks of time since there were 822 words in total to review. The vocabulary pool total word count was initially 32,941 and was minimized to 4,814 words (1,045 words for 50-58 month-olds, 1,604 words for 58-66 month-olds and 2,165 words for 66-74 month-olds.) The latest form of the vocabulary list was created by limiting to the most frequent 822 words in the course books analyzed, and was presented to ten academicians from child development and preschool departments.

These ten academicians participated and completed a rating form including three main considerations:

- “importance level for instruction" scored as significant (1), insignificant (2) 
- "difficulty level" scored as easy-close environment (1), medium-further environment (2), difficult-furthest environment (3)

- $\quad$ “age-appropriateness level" scored as appropriate (1), and inappropriate (2).

Additionally, the experts were asked to write a brief description explaining why they think the item is "least appropriate or top significant." At this stage, the experts participating in Delphi Panel had no interaction. The academicians evaluated the pilot test independently.

The RUBRIC developed to guide the raters and some sample words for each group of age related to nouns

\begin{tabular}{|c|c|c|c|c|c|c|c|}
\hline \multirow[t]{2}{*}{ AGE 4/NOUNS } & \multicolumn{2}{|c|}{ Significance Level } & \multicolumn{3}{|c|}{ Difficulty Level } & \multicolumn{2}{|c|}{$\begin{array}{c}\text { Age Appropriateness } \\
\text { Level }\end{array}$} \\
\hline & Significant(1) & Insignificant(2) & \begin{tabular}{|c} 
Easy (Close \\
Environment) \\
$(1)$
\end{tabular} & \begin{tabular}{|l} 
Medium (Further \\
Environment) \\
(2)
\end{tabular} & $\begin{array}{l}\text { Difficult } \\
\text { (Furthest } \\
\text { Environment) }\end{array}$ & $\begin{array}{l}\text { Appropriate } \\
\text { (1) }\end{array}$ & $\begin{array}{l}\text { Inappropriate } \\
(2)\end{array}$ \\
\hline \multicolumn{8}{|l|}{ 01. child } \\
\hline \multicolumn{8}{|l|}{ 02. picture } \\
\hline \multicolumn{8}{|l|}{ 03. book } \\
\hline \multicolumn{8}{|l|}{ 51. clothes } \\
\hline 52. butterfly & & & & & & & \\
\hline 53. puppy & & & & & & & \\
\hline
\end{tabular}

\begin{tabular}{|c|c|c|c|c|c|c|c|}
\hline \multirow[t]{2}{*}{ AGE 5/NOUNS } & \multicolumn{2}{|c|}{ Significance Level } & \multicolumn{3}{|c|}{ Difficulty Level } & \multicolumn{2}{|c|}{$\begin{array}{c}\text { Age } \\
\begin{array}{c}\text { Appropriateness } \\
\text { Level }\end{array} \\
\end{array}$} \\
\hline & $\begin{array}{l}\text { Significant } \\
\text { (1) }\end{array}$ & $\begin{array}{l}\text { Insignificant } \\
(2)\end{array}$ & $\begin{array}{l}\text { Easy (Close } \\
\text { Environment) } \\
(1)\end{array}$ & $\begin{array}{l}\text { Significant } \\
\text { (1) }\end{array}$ & $\begin{array}{l}\text { Insignificant } \\
\text { (2) }\end{array}$ & $\begin{array}{l}\text { Easy (Close } \\
\text { Environment) } \\
\text { (1) }\end{array}$ & $\begin{array}{l}\text { Significant } \\
\text { (1) }\end{array}$ \\
\hline \multicolumn{8}{|l|}{ 01. noise } \\
\hline \multicolumn{8}{|l|}{ 02. line } \\
\hline \multicolumn{8}{|l|}{ 03. wrong } \\
\hline \multicolumn{8}{|l|}{ 191.Children's Day } \\
\hline 192.Ramadan Feast & & & & & & & \\
\hline 193.Sacrifice Feast & & & & & & & \\
\hline
\end{tabular}

\begin{tabular}{|l|l|l|l|l|l|l|l|}
\hline \multicolumn{2}{|c|}{ AGE 6/NOUNS } & \multicolumn{2}{|c|}{ Significance Level } & \multicolumn{2}{c|}{ Difficulty Level } & \multicolumn{2}{c|}{$\begin{array}{l}\text { Age Appropriateness } \\
\text { Level }\end{array}$} \\
\hline & Significant(1) & Insignificant(2) & $\begin{array}{l}\text { Easy (Close } \\
\text { Environment) } \\
(1)\end{array}$ & $\begin{array}{l}\text { Significant } \\
\text { (1) }\end{array}$ & $\begin{array}{l}\text { Insignificant (2) } \\
\text { (1) }\end{array}$ & $\begin{array}{l}\text { Easy (Close } \\
\text { Environment } \\
(1)\end{array}$ & $\begin{array}{l}\text { Significant } \\
(1)\end{array}$ \\
\hline 01. piece & & & & & & & \\
\hline 02. creature & & & & & & & \\
\hline 153. result & & & & & & & \\
\hline 154. Republic Day & & & & & & & \\
\hline
\end{tabular}

The test evaluation results obtained via the Delphi Technique via the rubric given above were compiled by two measurement evaluation experts and by lecturers on the thesis monitoring committee. Within this group a common view was determined about the time spent on applying the scale, whether the test items are suitable for the preschool age group, the difficulty levels of the items and whether the words are listed appropriately. At this stage, in order to test the consistency of the decisions that experts made (in terms of the dimensions of "Significance Level", "Difficulty Level" and "Age Appropriateness Level" for each word) the Content Validity Index was calculated and the coefficient was found as 0.89 . This value indicates that the expert and observer decisions made for the appropriateness of the words are at a high level. 
In this way, with the opinions of the experts in the Delphi Panel and academicians in the fields of child development and assessment and evaluation, it has been decided that the test has the content validity both as a whole, as well as item by item.

\section{Illustration Study}

At this stage, preparations such as selecting pictures, photographing images, choosing color, size ratios, etc. for all the concepts in the scale are made with a visual design expert from the faculty of fine arts, a teacher who leads drawing classes in a preschool and a measurement evaluation expert. The appropriateness of all the images in the scale in terms of development and age characteristics of the children were examined and the images that provided the visual stimuli were included in the scale. In this way all the concepts in the scale are transformed into color photographs.

\section{Pilot Study}

LFFLAS was applied in a pilot group on 5 children who were 50-74 months-old, and the necessary changes were made. Five pictures were changed (car, chair, balloons, world and flower) and one was just taken out (mini-bus). There were two preschool teachers as observers accompanying the researcher during the pilot study. The teachers were also given the opportunity to practice giving the scale after observing how the application is carried out, how long it took, how the questions were asked. They were not allowed to proceed until they showed competency in applying the scale. At this stage, the following features were observed; whether or not the children could understand the questions that are in the communicative language part of the scale; whether or not they could say the right word for the picture shown in the expressive language part of the scale, whether they could understand the directions given and show the right picture or not in the receptive language part of the scale. It is seen that all the children responded to the items in the scale during the pilot study and the administration lasted about 20 minutes. After this application the scale is applied individually on 120 children between the ages of 50-74 months in the 2014-2015 academic year in 4 preschool education institutions. During the application, the classroom teachers of the children were present.

\section{The application of the scale}

The Life-Focused Foreign Language Acquisition Scale was created to measure children's English language acquisition as a foreign language. The scale consists of three sections:

- $\quad$ "Knowing Self" comprised 11 questions,

- $\quad$ "Useable Vocabulary" comprised of 28 questions, and

- "Recognizable Vocabulary" comprised of 39 questions

The first two sections assess expressive vocabulary and the third section assesses receptive vocabulary. During the application, sets of photos are presented in the second and third sections of the scale. In section two, a photo is shown to the child and the child is asked to name the word that corresponds to the photo. In the third part the child is asked to point to the photo that matches the word spoken by the researcher in English regarding receptive vocabulary. Children left their classroom with the researcher hand in hand in a friendly way. The scale is applied in the libraries of the schools which were on the same floor. So the setting was close and familiar to the child. There were no corrections or any criticism after children's responses. Any child that appeared uncomfortable would be promptly returned to his/her classroom. During the application an observer recorded the child responses to each of the photos presented. This information is used to identify additional acceptable alternatives for some stimulus photos. For instance, "mommy" was suggested an acceptable alternative response to the stimulus photo 
for "mother" based on the responses children gave during the pilot study. Additional direction is given before beginning the administration of the scale to make sure that the child understands the task. During the administration of the scale, a checklist was completed by the researcher and each correct answer coded as (1), and every wrong or uncertain answer is coded as (0).

After the pilot application of the scale on 120 preschoolers, the analyses were made on each of the individual items and on the whole scale. According to the results, the difficulty levels (pj) of the final items ranged from 0.05 to 0.67 and the discriminative powers (rjx) ranged from 0.30 to 0.70 . Thus, 78 items were included and formed the Life-Focused Foreign Language Acquisition Scale.

\section{Factor Analysis}

Due to the 1-0 scoring of the scale (dichotomous data), a Tetrachoric Factor Analysis was performed on this matrix was established in the present study. Before applying Tetrachoric Factor Analysis on 78 items, Kaiser-Meyer-Olkin (KMO) and Barlet Test values were calculated. The results were found to be 0,845 for KMO value and 18256,43 ( $p<0,01$ ) for the Barlett test value. According to these values, the sample is suitable for the test developed and factor analysis can be applied. After applying Factor Analysis, it is seen that the scale has 4 sub-dimensions as shown in the graphic below. The variance explained by the eigenvalue is $54.78 \%$. According to these findings, it can be said that the feature that was meant to be explained by the scale is tested at high explanatory level, so therefore the construct validity of the scale is high.

For the items in this scale, 0,35 coefficient is taken as the cut-off point. As a result of Component and Varimax Factor Analysis, two items were subtracted from the scale because they had a factor load below the 0.35 cut-off point. Eigen value (eigenvalue) of the Kaiser show that the scale has 4 sub-factors. The first factor of the scale describes $26.09 \%$ of the total variance, the second factor describes $13.03 \%$, the third factor describes $9.85 \%$ and finally the 4 th factor describes $5.87 \%$ of the total variance. In this way, the 4 dimensions of the scale explain about $55 \%$ of preschool language acquisition. From this aspect, the variance that is explained is at a high level. As a result of Tetraconic, factor loadings that are found higher than 0.35 and items in 4 dimensions, items remaining and item total correlation coefficients and factor load results are shown in the following chart. The factor analysis results of Life-Focused Foreign Language Acquisition Scale are shown below in Table 6.

Table 6. Factor and Item Analysis Results of the Life-Focused Foreign Language Acquisition Scale

\begin{tabular}{llll}
\hline Sub-Scale & $\begin{array}{c}\text { Tetrachoric } \\
\text { Factor Load }\end{array}$ & Pj & rjx \\
\hline $1^{\text {st }}$ subscale & & & 0.60 \\
\hline b3_9 & 0.87 & 0.27 & 0.67 \\
b2_17 & 0.72 & 0.30 & 0.46 \\
b3_8 & 0.67 & 0.34 & 0.62 \\
b3_6 & 0.65 & 0.34 & 0.66 \\
b3_18 & 0.58 & 0.27 & 0.50 \\
b2_22 & 0.54 & 0.20 & 0.77 \\
b3_32 & 0.50 & 0.41 & 0.65 \\
b3_5 & 0.49 & 0.36 &
\end{tabular}




\begin{tabular}{|c|c|c|c|}
\hline Sub-Scale & $\begin{array}{l}\text { Tetrachoric } \\
\text { Factor Load }\end{array}$ & $\mathrm{Pj}$ & rjx \\
\hline b2_16 & 0.42 & 0.19 & 0.51 \\
\hline b2_12 & 0.41 & 0.24 & 0.56 \\
\hline b2_8 & 0.37 & 0.21 & 0.48 \\
\hline b3_33 & 0.37 & 0.12 & 0.58 \\
\hline b2_4 & 0.37 & 0.35 & 0.51 \\
\hline b3_4 & 0.37 & 0.42 & 0.61 \\
\hline b2_21 & 0.36 & 0.25 & 0.46 \\
\hline b3_34 & 0.36 & 0.29 & 0.65 \\
\hline b3_30 & 0.36 & 0.18 & 0.52 \\
\hline b3_19 & 0.36 & 0.22 & 0.64 \\
\hline b2_24 & 0.36 & 0.26 & 0.63 \\
\hline b3_27 & 0.36 & 0.11 & 0.35 \\
\hline b2_23 & 0.35 & 0.24 & 0.60 \\
\hline b2_18 & 0.35 & 0.12 & 0.42 \\
\hline b3_17 & 0.35 & 0.09 & 0.42 \\
\hline b1_4 & 0.35 & 0.26 & 0.65 \\
\hline \multicolumn{4}{|c|}{$2^{\text {nd }}$ Sub-Scale } \\
\hline b3_14 & 0.88 & 0.62 & 0.65 \\
\hline b2_7 & 0.84 & 0.62 & 0.59 \\
\hline b2_25 & 0.84 & 0.54 & 0.74 \\
\hline b2_6 & 0.83 & 0.51 & 0.66 \\
\hline b3_21 & 0.81 & 0.60 & 0.68 \\
\hline b2_11 & 0.79 & 0.64 & 0.61 \\
\hline b2_1 & 0.78 & 0.50 & 0.62 \\
\hline b3_26 & 0.77 & 0.38 & 0.49 \\
\hline b1_1 & 0.76 & 0.62 & 0.58 \\
\hline b3_23 & 0.76 & 0.52 & 0.47 \\
\hline b2_2 & 0.75 & 0.59 & 0.51 \\
\hline b3_12 & 0.74 & 0.78 & 0.58 \\
\hline b3_7 & 0.74 & 0.52 & 0.56 \\
\hline b3_28 & 0.74 & 0.31 & 0.44 \\
\hline b3_3 & 0.73 & 0.44 & 0.54 \\
\hline b3_1 & 0.72 & 0.62 & 0.46 \\
\hline
\end{tabular}




\begin{tabular}{|c|c|c|c|}
\hline Sub-Scale & $\begin{array}{l}\text { Tetrachoric } \\
\text { Factor Load }\end{array}$ & $\mathrm{Pj}$ & rjx \\
\hline b2_9 & 0.72 & 0.37 & 0.51 \\
\hline b3_13 & 0.71 & 0.27 & 0.58 \\
\hline b2_10 & 0.68 & 0.51 & 0.48 \\
\hline b3_2 & 0.66 & 0.34 & 0.54 \\
\hline b2_3 & 0.65 & 0.75 & 0.59 \\
\hline b1_3 & 0.61 & 0.73 & 0.53 \\
\hline b3_10 & 0.61 & 0.59 & 0.46 \\
\hline b2_15 & 0.44 & 0.23 & 0.36 \\
\hline \multicolumn{4}{|c|}{$3^{\text {rd }}$ Sub-Scale } \\
\hline b1_8 & 0.83 & 0.15 & 0.50 \\
\hline b1_7 & 0.81 & 0.27 & 0.60 \\
\hline b1_6 & 0.79 & 0.22 & 0.58 \\
\hline b1_9 & 0.79 & 0.11 & 0.42 \\
\hline b3_24 & 0.75 & 0.09 & 0.54 \\
\hline b2_20 & 0.74 & 0.12 & 0.53 \\
\hline b3_37 & 0.71 & 0.25 & 0.53 \\
\hline b2_28 & 0.70 & 0.12 & 0.41 \\
\hline b2_5 & 0.69 & 0.08 & 0.49 \\
\hline b3_31 & 0.69 & 0.05 & 0.34 \\
\hline b1_10 & 0.68 & 0.17 & 0.55 \\
\hline b2_14 & 0.66 & 0.24 & 0.46 \\
\hline b2_13 & 0.66 & 0.13 & 0.45 \\
\hline b1_5 & 0.61 & 0.23 & 0.50 \\
\hline b3_38 & 0.58 & 0.07 & 0.35 \\
\hline b1_2 & 0.56 & 0.22 & 0.46 \\
\hline b2_19 & 0.55 & 0.12 & 0.37 \\
\hline b3_22 & 0.40 & 0.07 & 0.43 \\
\hline b3_29 & 0.38 & 0.09 & 0.42 \\
\hline \multicolumn{4}{|c|}{$4^{\text {th }}$ Sub-Scale } \\
\hline b3_25 & 0.86 & 0.24 & 0.52 \\
\hline b3_16 & 0.76 & 0.15 & 0.63 \\
\hline b3_15 & 0.71 & 0.20 & 0.51 \\
\hline b2_26 & 0.63 & 0.34 & 0.54 \\
\hline b3_20 & 0.61 & 0.22 & 0.44 \\
\hline
\end{tabular}




\begin{tabular}{lccc}
\hline Sub-Scale & $\begin{array}{c}\text { Tetrachoric } \\
\text { Factor Load }\end{array}$ & Pj rjx \\
\hline b1_11 & 0.59 & 0.21 & 0.64 \\
b3_11 & 0.45 & 0.23 & 0.50 \\
b2_27 & 0.45 & 0.14 & 0.50 \\
b3_39 & 0.41 & 0.16 & 0.51 \\
b3_36 & 0.38 & 0.18 & 0.49 \\
b3_35 & 0.37 & 0.17 & 0.48 \\
\hline
\end{tabular}

\section{Known Group Validity}

The construct validity of the LFFLAS is tested by factor and item analysis techniques and a high validity level is obtained. Another way of testing the theoretical validity of the scale is the method of "known group validity." For this purpose, this method has been applied in a preschool education institution where they teach English as a foreign language. The developed scale is applied to 3 groups of children, 15 of whom were previously classified as high, medium and low by teachers in terms of their foreign language levels. As seen in the graphic and in Table 3, high, medium and low scores were found to be equal to the grades of the teachers not only in all the sub-scales of the foreign language acquisition scale but also in its total scores. The children, who were classified as having a high foreign language level by their teachers, got also high scores from the developed scale. These results show that the Life-Focused Foreign Language Acquisition Scale has "known group validity" at a high level.

Table 7. Known Group Validity Results of Life-Focused Foreign Language Acquisition Scale

\begin{tabular}{|c|c|c|c|c|c|c|}
\hline \multicolumn{2}{|c|}{ Known Group Validity } & $\begin{array}{l}\text { Total } \\
\text { Score }\end{array}$ & $\begin{array}{c}\text { Sub-Scale } \\
\text { I }\end{array}$ & $\begin{array}{c}\text { Sub-Scale } \\
\text { II }\end{array}$ & $\begin{array}{c}\text { Sub-Scale } \\
\text { III }\end{array}$ & Sub-Scale IV \\
\hline \multirow{3}{*}{ Low } & Mean & 15.80 & 1.80 & 11.40 & 2.00 & 0.73 \\
\hline & $\mathrm{n}$ & 15 & 15 & 15 & 15 & 15 \\
\hline & Std. Deviation & 4.93 & 1.42 & 2.85 & 2.13 & 0.59 \\
\hline \multirow{3}{*}{ Medium } & Mean & 33.07 & 6.40 & 18.80 & 6.00 & 2.60 \\
\hline & $\mathrm{n}$ & 15 & 15 & 15 & 15 & 15 \\
\hline & Std. Deviation & 9.12 & 3.85 & 2.73 & 3.70 & 1.92 \\
\hline \multirow{3}{*}{ High } & Mean & 43.87 & 8.73 & 21.93 & 9.47 & 4.80 \\
\hline & $\mathrm{n}$ & 15 & 15 & 15 & 15 & 15 \\
\hline & Std. Deviation & 13.27 & 5.05 & 1.43 & 5.95 & 2.54 \\
\hline \multirow[t]{2}{*}{ Kruskal } & $\mathrm{X} 2$ & 29.43 & 19.83 & 32.84 & 18.60 & 19.32 \\
\hline & $\mathrm{p}$ & 0.00 & 0.00 & 0.00 & 0.00 & 0.00 \\
\hline
\end{tabular}




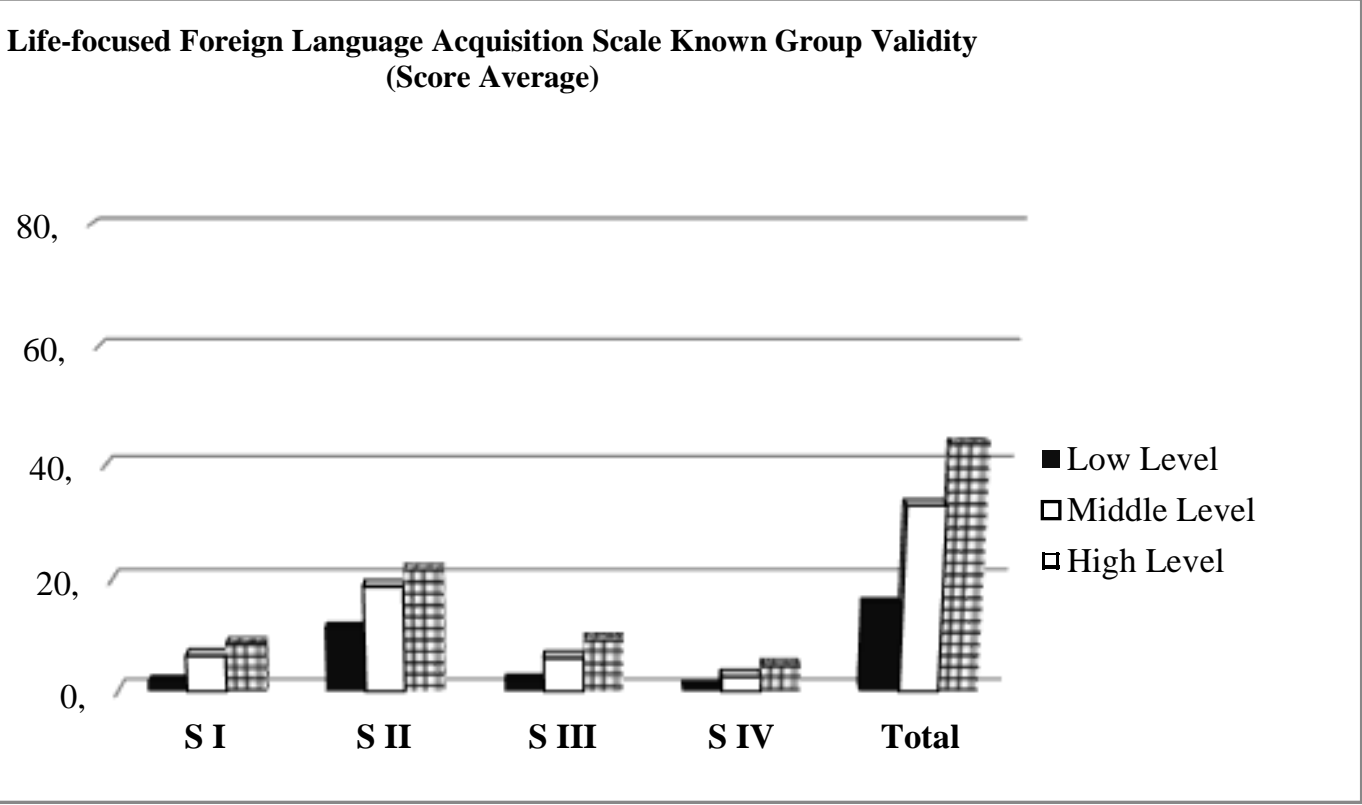

\section{Findings related to reliability}

For the present scale, the inter-rater reliability coefficient and the KR-20 reliability coefficient for each sub-scale were calculated. In order to calculate the inter-rater reliability coefficient between the practitioners, there were two experts for scoring and two for observing in the application. Afterwards, all scale applications were recorded with the camera placed in the application environment. Recordings of scale applications were monitored by two independent observers that are experienced in foreign language education independently and the Inter-Applicant Reliability Form prepared by the researcher is completed. The application reliability of each item of the scale is calculated by comparing the forms filled in by the independent observers. In the reliability calculations between practitioners, the formula of Agreement + Dissensus X 100 (Miles \& Huberman, 1994) is used. After the calculations, the reliability between practitioners is found as $93.8 \%$. This compliance coefficient is expected to be $70 \%$ or above. It can be concluded that the reliability of the Life-Focused Foreign Language Acquisition Scale is very high.

The reliability of a measurement tool is calculated by various methods, of which the most common of them is internal consistency method (Sünbül, 2004). In this scale, the KR-20 internal consistency coefficient was calculated both for the whole and for the sub-tests to measure the reliability. The KR-20 value is a coefficient ranging from -1 to 1 , and the reliability of the scale is considered to be high as this number approaches 1.

The KR-20 value for the whole scale is 0.95 . This indicates a high reliability value. The reliability of the subscales is 0.90 in the first dimension, 0.96 in the second dimension, 0.91 in the third dimension and 0.89 in the fourth dimension. Similar to KR-20 reliability results sub-scale split-half reliability (Spearman Brown) coefficient calculations were also between 0,91-0,97. The following table shows the item difficulty (pj) and item discrimination levels for all items of the scale. The level of substance discrimination is important in these kinds of scales and the value is desired to be over 0.30. Considering the items of this scale, the substance discrimination is found between 0,35 and 0,70 revealing that all of the items in the scale are highly distinguishable.

In conclusion, when the results obtained from the validity and reliability analyzes for LFFLAS are viewed in a holistic way it is seen that the three-factor structure of the scale was a valid model and reliable to evaluate 54-72 months old children's foreign language acquisition. 
Foreign Language Acquisition of Preschool Children According to Their Genders

Table 8. Comparison of Preschoolers' Foreign Language Acquisition In Terms of Gender

\begin{tabular}{lcccccc}
\hline Sub-Scale & Gender & $\mathrm{n}$ & Mean & $\begin{array}{l}\text { Standard } \\
\text { Devia- } \\
\text { tion }\end{array}$ & $\mathrm{t}$ & $\mathrm{p}$ \\
\hline Sub-scale 1 & Girl & 55 & 2.65 & 4.36 & 1.00 & 0.31 \\
& Boy & 66 & 1.93 & 3.47 & & \\
Sub-scale 2 & Girl & 55 & 8.98 & 8.77 & 1.17 & 0.24 \\
& Boy & 66 & 7.21 & 7.86 & & \\
Sub-scale 3 & Girl & 55 & 2.42 & 4.61 & 0.52 & 0.60 \\
& Boy & 66 & 2.02 & 3.84 & & \\
Sub-scale 4 & Girl & 55 & 1.44 & 2.12 & 1.83 & 0.04 \\
& Boy & 66 & 0.79 & 1.83 & & \\
Total & Girl & 55 & 15.27 & 17.99 & 1.17 & 0.24 \\
& Boy & 66 & 11.70 & 15.49 & & \\
\hline
\end{tabular}

Independent sample t test technique was used to compare preschool children's foreign language acquisition regarding gender variable. According to the results of the analysis, there were no significant differences in terms of gender variable in the 1st, 2 nd, 3 rd sub-dimensions and total scores of the scale. However, a significant difference is found in the 4 th sub-scale of the scale regarding gender ( $t=1.83, p=$ 0.049). In the "Useful Vocabulary" sub-scale, girls had significantly higher scores on foreign language acquisition than boys. 
Foreign Language Acquisition of Preschool Children According to Their Ages

Table 9. The Relationship between Preschool Children's Foreign Language Acquisition and Their Ages

\begin{tabular}{lll}
\hline & \multicolumn{3}{c}{ Sub-Scale Scores x Age } \\
\hline Sub-scale 1 & $-r-$ & $-p-$ \\
Sub-scale 2 & $0.297^{* *}$ & 0.001 \\
Sub-scale 3 & 0.127 & 0.166 \\
Sub-scale 4 & $0.228^{*}$ & 0.012 \\
\hline Total & $0.235^{* *}$ & 0.009 \\
\hline
\end{tabular}

The correlation coefficient between preschool children's ages (in months) and their foreign language acquisition scores is given in the table above. According to the results of the analysis, a significant and positive correlation is found in Vital Vocabulary, Social Vocabulary, Useful Vocabulary sub-scale scores and total scores and the age variable. As children got older, their foreign language acquisition scores also increased.

\section{DISCUSSION \& CONCLUSION}

The purpose of the present study was to develop a LFFLAS developed for the evaluation of foreign language acquisition in the preschool period. In line with the general purpose, 120 children that are 50-74 months-old and attending Kindergartens that are affiliated under the Ministry of National Education in Konya are included in the study. Within the context of the study, four sub-tests named as Vital Vocabulary, Crucial Vocabulary, Social Vocabulary and Useful Vocabulary are developed to evaluate foreign language acquisition of preschool children. To provide the validity of the scale, content validity (Delphi Panel, Expert Opinions), construct validity (descriptive factor analysis), Known Group Validity (correlations between subtests and criterion), item difficulty level and substance discrimination indices are calculated. The reliability analysis of the scale is conducted by calculating internal consistency (KR-20) and split-half reliability (Spearman Brown) coefficients.

The experts who participated in the Delphi Panel to express opinions regarding the validity of LifeFocused Foreign Language Acquisition Scale developed for preschool children suggested that each item in the sub-tests of the scale reflect children's competences in the relevant tests. In this respect, it is accepted that the LFFLAS adequately reflects the desired areas. For the construct validity of the scale, exploratory factor analysis is applied and it is found that the scale consists of four sub-tests. The factor loadings of the items in each sub-test vary between .35 and .87 and the sub-tests give the expected internal agreement within themselves. According to these results, the construct validity of the LFFLAS is accepted as highly sufficient. When children's scores are compared in terms of gender variable, no significant difference was found in Vital Vocabulary, Crucial Vocabulary and Social Vocabulary sub-tests and total scores. On the other hand, in the "Useful Vocabulary" sub-test a significant difference was found in favor of girls. In this 4 th dimension, girls received higher foreign language acquisition scores than boys. There was also a significant relationship between children's age and their foreign language acquisition scores except for the 2 nd sub-scale. The high level and meaningful correlations between the scores obtained from the sub-tests of the scale and the criterion test scores provided evidence for the validity of the foreign language acquisition test. Based on the findings of the study, it can be said that the 78-item scale is a reliable and valid scale. 


\section{Acknowledgments and Notes}

The present article is derived from the first author 's Ph.D. thesis with the title - The Study of the Effects of Life-Focused Language Acquisition Program on 50-74 Months Old Turkish Children's English Learning and the dissertation is financially supported by Selçuk University Coordinatorship of Scientific Research Projects (BAP) with the Project number 16102002.

\section{References}

Bacon, D. R., Sauer, P. L., \& Young, M. (1995). Composite Reliability in Structural Equations Modeling. Educational \& Psychological Measurement, 55, 394-406.

Bialystok, E. (2010). Global-Local And Trail-Making Tasks by Monolingual and Bilingual Children: Beyond inhibition. Developmental Psychology, 46, 93-105.

Bialystok, E., \& Martin, M. M. (2004). Attention and İnhibition In Bilingual Children: Evidence from the Dimensional Change Card Sort Task. Developmental Science, 7, 325-339.

Black, M. M.(2004). Commonly Used Assessment and Screening Instruments. HIPPY USA

Bekleyen, N. (2016). Foreign Language Teaching to Children. Ankara: Anı Publications

Boehm, A. (2001). Boehm Test of Basic Concepts 3-Preschool Version. New York: Psychological Corporation.

Büyüköztürk, Ş. (2004). Data Analysis Handbook. Ankara: Pegema Publications.

Brown, H. D. (2004). Language Assessment Principles and Classroom Practices. White Plains, NY: Pearson Education. Bzoch, K., League, R., \& Brown, V. (2003). Receptive-Expressive Emergent Language Test (3rd Ed.). Austin, TX: PRO-

ED.

Descoeudres, A. (1930). Test de Descoeudres.

Dunn, L. M., \& Dunn, L. M. (1997). Peabody Picture Vocabulary Test (3rd Ed.). Circle Pines, MN: American Guidance Service.

Fremer, J., \& Wall, J. (2004). Why use tests and assessments: Questions and answers. In J. Wall \& G. Walz (Eds.),

Measuring up: Assessment issues for teachers, counselors and Administrators (pp. 3-19). Greensboro, NC: ERIC Counseling and Student Services Clearinghouse

Hendrick, D., Prather, E., \& Tobin, A. (1984). Sequenced Inventory of Communication Development (Rev. Ed.). Austin, TX: PRO-ED.

Hresko, W., Reid, D. K., \& Hammill, D. (1999). Test of Early Language Development (3rd Ed.) New York: Psychological Corpo-ration.

Invernizzi, M., Sullivan, A., \& Meier, J. (2001). Phonological awareness literacy screening (PALS Pre-K). Charlottesville: University of Virginia Press.

Krashen, Stephen D. (1981). Second Language Acquisition \& Second Language Learning. University of Southern California. Pergamon Press Inc.

Lightbown, P. \& Spada, N. (1999) How Languages are Learned. Oxford: Oxford University Press.

Limbosch, N., Luminet-Jasinski, A. \& Dierkens-Dopchie, N. (1968). La dsylexie â l'ecole primaire. Bruxelles: Editions de L'Institut de Sociologie

Love, J.M. (2001). Instrumentation for State Readiness Assessment: Issues in Measuring Children's Early Development \& Learning. Mathematica Policy Research. Princeton, NJ.

McMillan, J. H. (2007). Classroom Assessment: Principles and Practice for Effective Standards-Based Instruction (4th Ed.). Boston, MA: Pearson Allyn and Bacon. 
Mann, T., \& Powers, S. (1997). Screening \& Assessment for Head Start Programs Serving Infants and Toddlers. Paper presented at the 24th National Head Start Association Training Conference. Boston, MA.

Martinez, J. M. \& Lesaux, K. L. (2011). Early Home Language Use and Later Vocabulary Development. Journal of Educational Psychology, 103, (3) 535-546.

MEB, (2013). Ministry of National Education General Directorate of Basic Education, Preschool Education Curriculum. Ankara.

Milton, J. (2009). Measuring Second Language Vocabulary Acquisition. Bristol: Multilingual Matters.

Milton, J., \& Daller, H. (2007). The Interface between Theory and Learning in Vocabulary Acquisition. Paper presented at the EUROSLA, Newcastle upon Tyne, UK.

Minami, M. (2002). Book Review. (Bialystok, Ellen (2001). Bilingualism in Development: Language, Literacy and Cognition. New York: Cambridge University Press.). Bilingual Research Journal, 26 (3), 729-735.

Muter, V., Hulme, C., \& Snowling, M. (1999). Phonological Abilities Test. San Antonio, TX: The Psychological Corporation.

Panter, A. T., Swygert, K. A., Dahlstrom, W. G., \& Tanaka, J. S. (1997). Factor Analytic Approaches to Personality ItemLevel Data. Journal of Personality Assessment, 68, 561-589.

Patterson, G.R., DeBaryshe, B. \& Ramsey, E. (1990). A Developmental Perspective on Antisocial Behavior. American Psychologist, 44, 329-335.

Pekrun, R. (2006) The Control-Value Theory of Achievement Emotions: Assumptions, Corollaries, and Implications for Educational Research and Practice. Educational Psychology Review, 18, (4), 315-341.

Pinter, A. (2011) Children Learning Second Languages. Centre for Applied Linguistics, University of Warwick, UK.

Reuterberg, S. \& Gustafsson, J.-E. (1992). Confirmatory Factor Analysis and Reliability: Testing Measurement Model Assumptions. Educational and Psychological Measurement, 52, 795-811.

Sawyer, D. J. (1987). Test of Awareness of Language Segments. Rockville, MD: Aspen

Shepard, L.A., Taylor, G.A., and Kagan, S.L. (1996). Trends in Early Childhood Assessment Policies and Practices. Boulder, CO: University of Colorado, School of Education.

Sünbül, A. M. (2004). Validity and Reliability of Thinking Styles Scale. Education and Science Journal, 132, 25-42

Thal, D.J., O'Hanlon, L., Clemmons, M. and Fralin, L. (1999). Validity of a Parent Report Measure of Vocabulary \& Syntax for Preschool Children with Language Impairment. Journal of Speech, Language \& Hearing Research, 42, 482-496.

Torgesen, J. K. \& Bryant B. R., (1994). Test of Phonological Awareness (TOPA). Austin, Tex.: Pro-Ed

VanTol, Kathleen M. (2009). Technical Adequacy of Curriculum-Based Measures of Vocabulary Growth for Preschool English Language Learners. PhD Dissertation. Western Michigan University, Kalamazoo, Michigan.

Yoneda, M. (2012). Designing Assessment Tools: The Principles of Language Assessment Bull. Mukogawa Women's Univ. Humanities and Social Sciences, 60, 41-49.

Wagner, R.K., Torgesen, J. K., and Rashotte, C.A. (1999). Comprehensive Test of Phonological Processing (CTOPP)

Willis, M., \& Ohashi, Y. (2012). A Model of L2 Vocabulary Learning and Retention. The Language Learning Journal, 40 (1), 125-137.

Zimmerman, I., Steiner, V., \& Pond, R. (2002). Preschool Language Scale (4th ed.) and Preschool Language ScaleSpanish Edition. New York: Psychological Corporation. 